\title{
Probable brote de transmisión oral de enfermedad de Chagas en Turbo, Antioquia
}

\author{
Juan Fernando Ríos ${ }^{1}$, Margarita Arboleda² Alba Nelly Montoya¹, Erika Patricia Alarcón², \\ Gabriel Jaime Parra-Henao² \\ 1 Programa de Control de Enfermedades Transmitidas por Vectores, Dirección Seccional de Salud de Antioquia - \\ Instituto Colombiano de Medicina Tropical, Medellín, Colombia \\ ${ }^{2}$ Laboratorio de Entomología Médica, Instituto Colombiano de Medicina Tropical, Universidad CES, Sabaneta, \\ Colombia
}

Lugar donde se realizó el trabajo: Instituto Colombiano de Medicina Tropical (ICMT), Laboratorio Departamental de Salud Pública de Antioquia e Instituto Nacional de Salud.

Introducción. La enfermedad de Chagas es endémica en 21 países de América, incluyendo a Colombia, donde 700.000 a 1'200.000 personas se encuentran infectadas y ocho millones están en riesgo. En las áreas endémicas predominan los casos crónicos infectados por vía vectorial. Sin embargo, en los últimos años se han incrementado los reportes de casos agudos ocurridos por transmisión oral.

Objetivos. Describir un brote agudo de enfermedad de Chagas en Turbo (Antioquia) y determinar la posible forma de transmisión para establecer mecanismos de prevención y control.

Materiales y métodos. Se hizo un estudio descriptivo. Se verificó la documentación del diagnóstico en los casos y se hizo búsqueda activa de pacientes sintomáticos y de los contactos; se realizaron pruebas de laboratorio, identificación de factores de riesgo y búsqueda de reservorios y vectores.

Resultados. Se evaluaron 156 personas, y se identificaron 11 casos agudos de enfermedad de Chagas, 10 con títulos de anticuerpos IgM e IgG contra Trypanosoma cruzi por IFI y ELISA, y un caso fallecido, asociado epidemiológicamente. En tres personas, la PCR para T. cruzi fue positiva, dos de ellas con miocardiopatía y otra con síndrome febril agudo. Cuatro casos requirieron manejo en hospital de tercer nivel por miocardiopatía aguda. Todos los casos positivos tenían fuente común de alimentación. Se recolectó un ejemplar de Panstrongylus geniculatus y uno de Caluromys lanatus, ambos negativos para $T$. cruzi.

Conclusión. Se identificó un probable brote agudo de enfermedad de Chagas en Antioquia y se plantea como hipótesis la transmisión por vía oral, mediante la ingestión de T. cruzi en alimentos contaminados con restos de triatominos o excrementos de marsupiales.

Palabras clave: Trypanosoma cruzi, cardiomiopatía chagásica, Triatominae, Panstrongylus, reservorios, marsupiales, Colombia.

\section{Probable outbreak of oral transmission of Chagas disease in Turbo, Antioquia}

Introduction. Chagas' disease is endemic in 21 countries of South and Central America, including Colombia, where 700,000 to 1.2 million persons are infected and eight millions are at risk. In endemic areas, chronic cases are predominant. However, in recent years, increasing reports of acute oral transmission have appeared.

Objective. An outbreak of acute Chagas' disease was verified in the municipality of Turbo (Antioquia), and the most probable cause of transmission was determined in order to establish prevention and control measures.

Materials and methods. A descriptive study was done. A search for information from local health authorities was conducted to uncover all case reports. Laboratory tests, risk factor analysis and search for vectors and reservoirs were undertaken in Turbo.

Results. Of the156 people evaluated, 11 cases of acute Chagas' disease were identified. Ten had significant titers of IgM and IgG antibodies against the Trypanosoma cruzi parasite by IFAT and Elisa tests; one fatal case was linked epidemiologically. In 3 cases, PCR was positive for T. cruzi, two of which displayed Chagas cardiomyopathy, and one with acute fever. Four cases required specialized health care for acute cardiomyopathy. All positive cases had a common source of food. One specimen of the triatomid vector species, Panstrongylus geniculatus, and one reservoir, the woolly opossum Caluromys lanatus, were collected; both were negative to $T$. cruzi.

Conclusions. An outbreak of acute Chagas' disease occurred in Turbo, Antioquia. The mode of transmission may have occurred by the ingestion of $T$. cruzi-contaminated food by infected triatomines or opossum feces. 
Key words: Trypanosoma cruzi, Chagas cardiomyopathy, Triatominae, Panstrongylus, reservoirs, marsupials, Colombia.

La enfermedad de Chagas es endémica en 21 de los 33 países de Centroamérica y Suramérica, se extiende desde México hasta el sur de Argentina y Chile, incluyendo a Colombia (PAHO/WHO. Update of American Trypanosomiasis and Leishmaniasis Control and Research: Final report. Report of the Scientific Meeting. Rio de Janeiro. Brazil, 6-7 November 2007). Las más recientes estadísticas epidemiológicas indican que, actualmente, hay entre 12 y 14 millones de personas infectadas, con una incidencia anual de 200.000 casos y miles de muertes; además, se estima que, aproximadamente, 28 millones de personas se encuentran en riesgo de contraer la infección por vía vectorial (1). En Colombia, los últimos reportes estiman que de 700.000 a 1.200 .000 personas se encuentran infectadas y ocho millones más están en riesgo de contraer la infección por vía vectorial (Padilla JC. Situación de la enfermedad de Chagas en Colombia. En: Guhl F. Primer taller internacional sobre control de la enfermedad de Chagas. Curso de diagnóstico, manejo y tratamiento de le enfermedad Chagas. Sexta reunión de la iniciativa para el control de la enfermedad de Chagas. Bogotá: Ed. Uniandes; 2005. p.17-23).

El hemoparásito Trypanosoma cruzi, agente etiológico de la enfermedad de Chagas, es transmitido por contacto con heces de insectos del orden Hemiptera, familia Reduviidae, subfamilia Triatominae, los cuales actúan como vectores potenciales y primarios del parásito (2). Actualmente, la subfamilia incluye 137 especies divididas en 6 tribus y 19 géneros (3), la mayoría de ellos vectores del parásito. Los géneros que presentan el mayor número de especies y que, a su vez, incluyen a los principales vectores, son Triatoma y Rhodnius (3).

En el departamento de Antioquia se ha registrado la presencia de 9 especies de triatominos, entre las cuales se han hallado vectores primarios: Rhodnius prolixus y Triatoma dimidiata; también, se han encontrado especies de hábitos principalmente selváticos, como Rhodnius pallescens, Triatoma venosa y Panstrongylus geniculatus, las cuales, eventualmente, pueden invadir las viviendas

Correspondencia:

Juan Fernando Ríos, Carrera 40 № 49-24, Medellín, Colombia Teléfono: (054) 239 6406; fax: (054) 2176657

juanfernandorios@gmail.com

Recibido: 12/07/10; aceptado:27/01/11 atraídas por la luz. En la subregión del Urabá antioqueño, se ha reportado la presencia de 6 especies de triatominos: Eratyrus cuspidatus, $P$. geniculatus, $R$. prolixus, $R$. pallescens, $T$. dimidiata y $T$. dispar, igualmente, se han reportado casos aislados de enfermedad de Chagas en los municipios de Chigorodó y Arboletes (Restrepo M, Restrepo BN, Parra GJ. Informe Final. Programa Nacional de Prevención y Control de la enfermedad de Chagas y la cardiopatía infantil. Antioquia, Córdoba, Bolívar. ICMT. 1999).

En las áreas endémicas, actualmente predominan los casos crónicos provenientes de infección por vía vectorial y, aun con los avances en el control de la enfermedad en países endémicos, ésta se mantiene como un proceso mórbido relevante para la salud pública. Sin embargo, en los últimos años, se han incrementado los reportes de casos agudos de la enfermedad de Chagas por transmisión oral en diferentes países. Storino y Jorg (4) recopilaron los trabajos de Natan-Larrier (5), Brumpt (6), Kofoid y Donat (7), y Cardoso (8), que pusieron a prueba la capacidad de infectar a los mamíferos con heces de triatominos, hasta la descripción de los primeros casos humanos por Mazza (9); además, añaden los trabajos posteriores de Mayer (10) y Díaz Ungría $(11,12)$, en los que observaron la infección de animales experimentales al ingerir alimentos contaminados con $T$. cruzi.

En Colombia, se han reportado cuatro brotes agudos de enfermedad de Chagas: el primero en 1992, en un grupo de soldados en Tibú, departamento del Norte de Santander, donde se confirmaron seis casos de miocarditis chagásica aguda y se estudiaron 144 soldados, $24(17 \%)$ con serología reactiva por IFI IgG. En $52 \%$ de los casos seropositivos hubo alteraciones electrocardiográficas (1). El segundo brote se dio en 1999 en Guamal (Magdalena) zona sin antecedentes de enfermedad de Chagas, en donde se reportaron 13 personas afectadas, que presentaron síndrome febril asociado a miocarditis aguda con cinco fallecimientos; como hipótesis se planteó la ingestión del parásito en vino obtenido de palma (13). El tercer brote se registró en el 2003 en Bucaramanga (Santander) con tres casos fatales (1), y el cuarto, en Lebrija (Santander) en el 2008, en el cual se confirmaron 10 casos, de los cuales, dos fallecieron (14). En ninguno de los casos de estos brotes se presentaron señales de puerta de entrada. Recientemente, se ha reportado un brote 
de enfermedad aguda de Chagas en Aguachica (Cesar) con 10 casos en un mismo núcleo familiar, al parecer por consumo de alimento en una celebración familiar (15).

El presente trabajo se desarrolló con el objetivo de describir un brote agudo de enfermedad de Chagas en el municipio de Turbo (Antioquia) y determinar la posible forma de transmisión, con miras a establecer los mecanismos de prevención y control necesarios.

\section{Materiales y métodos}

\section{Área de estudio}

El área de estudio está ubicada en jurisdicción del corregimiento de Bocas del Atrato, perteneciente al municipio de Turbo. Este corregimiento tiene una temperatura promedio de $30{ }^{\circ} \mathrm{C}$, humedad relativa de $88,5 \%$ y una altura sobre el nivel medio del mar de $2 \mathrm{~m}$; se encuentra localizado en las coordenadas geográficas $8^{\circ} 5^{\prime} 48,9^{\prime \prime} \mathrm{N}$ y $76^{\circ} 44^{\prime}$ 23,1 "W, sobre ambas riberas del brazo Coquitos, una de las desembocaduras del río Atrato, en la banda occidental del golfo de Urabá (figura 1).

\section{Descripción del brote}

El 18 de enero de 2010, la Secretaría de Salud y Protección Social de Antioquia recibió información sobre la necesidad de remitir a un hospital de tercer nivel de atención un paciente de 52 años (caso índice), con cardiopatía y resultado de 1:64 y 1:256 de anticuerpos IgM e IgG para $T$. cruzi por inmunofluorescencia indirecta (IFI), respectivamente, procedente del corregimiento Bocas de Atrato del municipio de Turbo. Este paciente estaba hospitalizado en la Clínica Chinita de Apartadó, donde había sido remitido por un cuadro febril de un mes de evolución acompañado de escalofríos, cefalea, malestar general, tos, dificultad respiratoria y hepatomegalia.

A raíz de esta notificación, se desarrollaron las siguientes actividades, con el fin de caracterizar la situación epidemiológica en este corregimiento.

Preparación de la investigación con estudio del caso notificado y búsqueda activa de casos adicionales mediante información en una Institución Prestadora de Salud (IPS) de los municipios de Turbo y Apartadó.

Definición de caso aguda sospechoso de enfermedad de Chagas: "Paciente que presenta 0 presentó cuadro febril o signos de falla cardíaca, hepatomegalia o esplenomegalia y que reside 0 visitó el corregimiento de Bocas del Atrato, en los meses de octubre, noviembre, diciembre de 2009 o

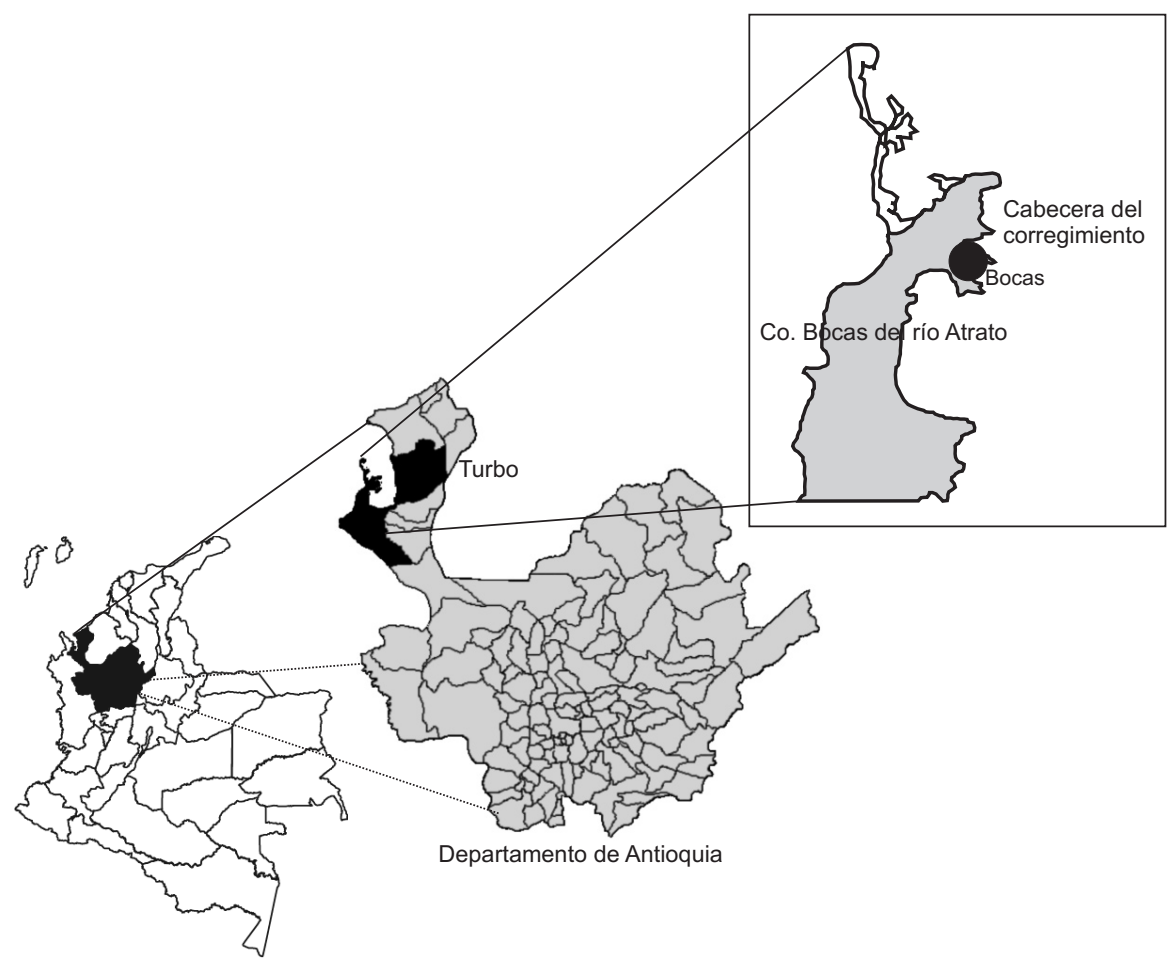

Figura 1. Área de estudio (corregimiento Bocas del Atrato, Turbo, Antioquia) 
enero de 2010". Como caso confirmado, se consideró todo caso sospechoso que se acompañara de pruebas serológicas positivas (IgM e lgG) por dos métodos diferentes, demostración parasitológica de infección por T. cruzi o PCR positiva.

Aplicación de encuesta clínico-epidemiológica a personas residentes en el corregimiento Bocas de Atrato, previo consentimiento informado. Esta encuesta incluía variables de identificación, antecedentes o presencia de síntomas de acuerdo con la definición de caso; asimismo, variables sobre ocupación, sitio de alimentación, consumo de alimentos, antecedentes de consumo de animales silvestres y nexo epidemiológico con el caso índice.

Estudio parasitológico, serológico y molecular de personas del corregimiento, sintomáticas y asintomáticas, previo consentimiento informado, mediante las técnicas que se mencionan a continuación.

Diagnóstico serológico. Detección de anticuerpos IgG e IgM mediante ELISA. Las muestras de suero obtenidas se procesaron para $\lg$ e $\operatorname{lgM}$, mediante la técnica $\operatorname{ELISA}(16,17)$ en el Laboratorio Departamental de Salud Pública de Medellín, de acuerdo con los protocolos establecidos por la casa comercial (Chagatek $\AA$, bioMérieux), utilizando un punto de corte correspondiente al promedio de las densidades ópticas de las muestras negativas + 100.

Detección de anticuerpos lg $G$ e $\lg M$ mediante inmunofluorescencia indirecta (IFI). Las muestras de suero se procesaron para detección de anticuerpos IgG e IgM mediante IFI, en el Instituto Colombiano de Medicina Tropical, de acuerdo con los protocolos estandarizados $(17,18)$. En esta técnica se utilizaron tripomastigotes de la cepa Medellín de T. cruzi, como antígenos, y un antiIgG e IgM humano (según el caso) marcado con isotiocianato de fluoresceína, como anticuerpo conjugado. El punto de corte establecido para esta prueba fue de 1:32.

Diagnóstico molecular. Reacción en cadena de la polimerasa. Para extraer el ADN se tomaron $5 \mathrm{ml}$ de sangre total con anticoagulante, los cuales se mezclaron por partes iguales con $6 \mathrm{M}$ de guanidina $\mathrm{HCl} / 0,2 \mathrm{M}$ EDTA, mezcla que se llevó a ebullición por 15 minutos y se refrigeró a $-20^{\circ} \mathrm{C}$. El ADN se purificó mediante extracción con fenol/cloroformo y se precipitó con etanol. Se hizo amplificación dirigida al fragmento de $330 \mathrm{pb}$ de ADN del minicírculo del cinetoplasto de $T$. cruzi $(19,20)$.
Esta prueba se practicó en el Instituto Colombiano de Medicina Tropical de Medellín.

Diagnóstico parasitológico. A las muestras positivas para IFI-lgM, se les practicó gota gruesa, extendido y concentración de Bennett, técnica que consiste en concentrar tripomastigotes en la zona limítrofe entre eritrocitos y plasma sanguíneo mediante centrifugación de sangre total en tubos capilares (21).

Muestreo de viviendas afectadas y vecinas: después de un censo detallado de la población, se hizo una búsqueda intensiva durante ocho días consecutivos de triatominos en el intradomicilio y el peridomicilio de la vivienda donde se alimentaban los casos y de 10 viviendas cercanas. Este muestreo se hizo inicialmente mediante inspección rigurosa de paredes, techo y enseres, con la ayuda de linterna y pinzas, de acuerdo con la metodología establecida por Organización Mundial de la Salud (OMS), 2002. Posteriormente, se rociaron todas las superficies con deltametrina al 2,5\% a manera de irritante, para obligar a los insectos a abandonar sus refugios y detectarlos con mayor facilidad.

Entrega de recipientes a la comunidad para la captura de triatominos: debido a que se ha demostrado la mayor sensibilidad de este tipo de muestreo sobre la búsqueda activa y el empleo de irritantes (22), se orientó a la comunidad en el reconocimiento de los vectores de enfermedad de Chagas y se les entregaron recipientes preparados para este fin, instruyéndolos en el cuidado de su captura y manipulación, y en la necesidad de entregarlos en el puesto de salud local.

Identificación taxonómica y análisis parasitológico de los triatominos: los insectos capturados fueron identificados hasta especie, mediante la clave de Lent y Wygodzinsky (23). De estos, se obtuvieron muestras de contenido intestinal para la búsqueda de flagelados.

Muestreo de vegetación (palmas y nidos en árboles): se revisaron exhaustivamente las palmas y la vegetación circundante al caserío.

Captura de mamíferos silvestres: durante cuatro noches consecutivas se instalaron trampas de tipo Tomahawk (dos cada noche) en los alrededores de las viviendas afectadas; las dos primeras noches se cebaron con papaya madura y las dos noches siguientes se empleó banano como atrayente. La ubicación de las trampas obedeció a las indicaciones de la comunidad sobre los sitios donde se habían observado animales silvestres, siendo 
así que se instalaron entre algunas macetas de un solar vecino y en una rama inferior del árbol de almendro de la casa del lugar de referencia común para todos los pacientes. Los animales capturados fueron sangrados mediante punción cardiaca, previa anestesia con una mezcla de ketamina y acepromazina (2 mg/kg) y se les hizo extendido de sangre y coloración con Giemsa.

Devolución de los resultados de los exámenes, orientación sobre tratamiento y realización de actividades de información y comunicación. Una vez procesados los exámenes, se captaron los pacientes ambulatorios, se encaminaron para tratamiento en las diferentes IPS, con medicamentos e instrucciones sobre dosificación y controles, suministrados por el Instituto Nacional de Salud, y se hizo intercambio de conocimientos sobre la enfermedad con la comunidad afectada.

\section{Consideraciones éticas}

La presente investigación se consideró de riesgo mínimo y cumplió con las normas éticas para la investigación en humanos contempladas en la Resolución 008430 de 1993 del Ministerio de Salud de Colombia. Todas las personas encuestadas dieron su consentimiento informado por escrito para participar en el estudio. Los procedimientos realizados para la obtención de sueros (venopunción) en animales se rigieron de acuerdo con la Ley 84 de 1989.

\section{Resultados}

La localidad de estudio posee una población aproximada de 350 habitantes, distribuidos entre la cabecera del corregimiento y las veredas Leoncito y El Roto. Su extensión es de $39.918 \mathrm{~m}^{2}$ y la mayoría de las 81 casas (de las cuales hay 5 deshabitadas) están construidas en madera, con piso del mismo material y techo de cinc. Carecen de energía eléctrica permanente, así como de acueducto y alcantarillado.

La formación vegetal corresponde a selva húmeda tropical, compuesta principalmente por grandes extensiones de mangle rojo (Rhizophora mangle) y de "arracacho" (Montrichardia arborescens), con parches de "palma pangana" (Raphia taedigera), "buchón de agua" (Eichornia crassipes) y algunos ejemplares aislados de cocoteros (Cocos nucifera), almendros (Terminalia catappa) y otras variedades de mangle (figura 2).

A raíz del caso probable de enfermedad Chagas notificado a la Secretaría de Salud y Protección

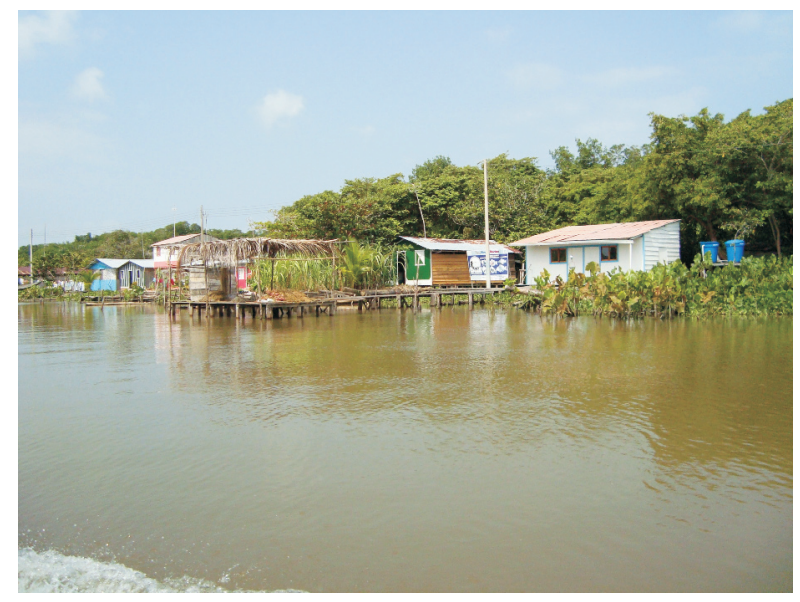

Figura 2. Panorámica del corregimiento Bocas del Atrato, Turbo, Antioquia

Social de Antioquia y durante el desarrollo de las actividades encaminadas a caracterizar el brote, se evaluaron 156 personas del corregimiento Bocas de Atrato, en 10 de las cuales se documentó la enfermedad aguda mediante pruebas de laboratorio, y se verificó el registro de un caso fatal con nexo epidemiológico con los casos, para un total de 11 casos agudos de enfermedad de Chagas incluyendo el caso índice y el caso fatal.

En el cuadro 1 se describen algunas características de los 11 pacientes en quienes se les documentó la enfermedad de Chagas. Diez de ellos fueron reactivos a las pruebas serológicas practicadas, por dos técnicas diferentes -ELISA e IFI- incluyendo tres casos con PCR positiva para T. cruzi, dos de los cuales presentaron miocardiopatía chagásica y otro con síndrome febril agudo; en ningún paciente se visualizó el parásito en el extendido de sangre, la gota gruesa o la prueba de Bennett. Cuatro tuvieron cuadro clínico de miocarditis aguda y requirieron manejo en un hospital de tercer nivel de atención. Los seis pacientes restantes tuvieron cuadros febriles agudos con manifestaciones generales, pero no requirieron manejo especializado y fueron manejados en las instituciones de salud de Turbo y Apartadó.

Un caso falleció en Medellín con síndrome febril agudo, escalofríos, cefalea, mialgias, artralgias, dolor abdominal y edema generalizado, pero desconociéndose otros detalles de su causa última de muerte. Este caso fatal también se alimentaba en la residencia ${ }^{* *}$ y trabajaba en la empresa de dragado. En el caso índice se descartó infección por leptospirosis, malaria y sepsis por gérmenes aerobios, y se reportaron simultáneamente anticuerpos IgM positivos para dengue. En otros 
Cuadro 1. Descripción de pacientes que cumplen con la definición de caso agudo de enfermedad de Chagas, corregimiento Bocas de Atrato, Turbo, 2009.

\begin{tabular}{|c|c|c|c|c|c|c|c|}
\hline Paciente & Edad & $\begin{array}{l}\text { Fecha de inicio } \\
\text { de los síntomas }\end{array}$ & Síntomas & $\begin{array}{l}\text { PCR } \\
\text { T. cruzi }\end{array}$ & $\begin{array}{l}\operatorname{Ig} M \\
\text { IFI }\end{array}$ & $\begin{array}{l}\operatorname{Ig} G \\
\text { IFI }\end{array}$ & $\begin{array}{l}\text { ELISA } \\
\lg M\end{array}$ \\
\hline 1 & 38 & 25 de octubre & $\begin{array}{l}\text { Fiebre, escalofríos, cefalea, } \\
\text { mialgias, artralgias, dolor } \\
\text { abdominal, edema generalizado** }\end{array}$ & No $R^{*}$ & No $R^{*}$ & No $R^{*}$ & No $R^{*}$ \\
\hline 2 & 32 & 30 de octubre & $\begin{array}{l}\text { Escalofríos, fiebre, cefalea, dolor } \\
\text { abdominal, artralgias }\end{array}$ & No $R^{*}$ & No $R^{*}$ & $1 / 64$ & Positivo \\
\hline 3 & 12 & 2 de noviembre & Fiebre y cefalea & Positiva & $1 / 32$ & $1 / 128$ & Positivo \\
\hline 4 & 52 & 2 de noviembre & $\begin{array}{l}\text { Fiebre, escalofríos, convulsiones, } \\
\text { cefalea, malestar, artralgias, } \\
\text { vómito, cardiopatía }\end{array}$ & Positiva & $1 / 64$ & $1 / 256$ & Positivo \\
\hline 5 & 10 & 4 de noviembre & $\begin{array}{l}\text { Fiebre, dolor abdominal, malestar, } \\
\text { cardiomegalia, edema orbicular } \\
\text { bipalpebral, bilateral, disnea }\end{array}$ & Positiva & $1 / 64$ & $1 / 256$ & Positivo \\
\hline 6 & 14 & 4 de noviembre & $\begin{array}{l}\text { Fiebre, dolor abdominal, malestar, } \\
\text { cardiomegalia, edema orbicular } \\
\text { bipalpebral bilateral, disnea }\end{array}$ & Negativa & $1 / 64$ & $1 / 256$ & Positivo \\
\hline 7 & 19 & 16 de noviembre & $\begin{array}{l}\text { Síndrome febril, cefalea, mialgias, } \\
\text { náuseas, vómito; la paciente } \\
\text { estaba en embarazo. }\end{array}$ & $N R^{*}$ & $1 / 64$ & $1 / 128$ & Positivo \\
\hline 8 & 60 & 18 de noviembre & $\begin{array}{l}\text { Fiebre, escalofríos, convulsiones, } \\
\text { cefalea, malestar, disnea, } \\
\text { cardiomegalia }\end{array}$ & No $R^{*}$ & No $R^{*}$ & $1 / 128$ & Positivo \\
\hline 9 & 31 & 19 de noviembre & $\begin{array}{l}\text { Fiebre, cefalea, falta de apetito, } \\
\text { artralgias, edema orbicular } \\
\text { bipalpebral bilateral, orina turbia }\end{array}$ & No $R^{*}$ & No $R^{*}$ & $1 / 128$ & Positivo \\
\hline 10 & 37 & 20 de noviembre & $\begin{array}{l}\text { Síndrome febril recurrente, mialgias, } \\
\text { artralgias, edema orbicular } \\
\text { bipalpebral bilateral, dolor abdominal, } \\
\text { malestar, escalofríos }\end{array}$ & No $R^{*}$ & $1 / 64$ & $1 / 128$ & Positivo \\
\hline 11 & 20 & 26 de noviembre & $\begin{array}{l}\text { Síndrome febril recurrente, mialgias, } \\
\text { artralgias, dolor abdominal, } \\
\text { escalofríos, malestar }\end{array}$ & Negativa & $1 / 64$ & $1 / 128$ & Positivo \\
\hline
\end{tabular}

* No R: no realizada

** Paciente con nexo epidemiológico, fallecido en Medellín el 25 de diciembre de 2009

dos casos hospitalizados en instituciones de salud de Apartadó, se descartó malaria y en uno de ellos se reportaron anticuerpos IgM positivos para leptospira, mediante ELISA. Todos los pacientes positivos recibieron tratamiento específico para enfermedad de Chagas.

El resto de pacientes evaluados (145/156) fueron negativos para anticuerpos $\lg M$ e $\operatorname{lgG}$ contra $T$. cruzi. Todos los casos positivos para enfermedad de Chagas se trataron con benznidazol, de acuerdo con los protocolos y guías estandarizadas por el Instituto Nacional de Salud.

La búsqueda en las IPS y en los certificados de defunción en los municipios de Turbo y Apartadó, no aportó casos diferentes a los identificados en la búsqueda en el corregimiento.
Todas las personas positivas, incluyendo el caso fatal, tenían como antecedente que se alimentaban en una misma casa: la casa **, lugar de referencia común para todos los pacientes. Los adultos trabajaban en la empresa de dragado del río Atrato; otras personas que trabajaban en la misma empresa, pero que se alimentaban en sitio diferente, fueron negativas para estos marcadores serológicos de infección. El total de personas expuestas fue de quince, once de las cuales desarrollaron la enfermedad, mientras que ninguna de las que se alimentaban en sitios diferentes a la vivienda **, se enfermó. La encuesta aplicada sobre consumo de alimentos (vino de palma, animales silvestres, verduras, frutas silvestres, pescado, plátano, etc.) no arrojó diferencias entre los positivos y negativos. 
En cuanto al muestreo entomológico, no se hallaron triatominos ni rastros de ellos en forma de exuvias, heces o huevos, mediante la búsqueda activa en ninguna de las casas. A partir de los recipientes entregados a la comunidad, se recibieron dos ejemplares adultos de $P$. geniculatus capturados en el interior de una vivienda por su moradora, además de ocho ejemplares que pertenecían a otros grupos taxonómicos de hemípteros (diferentes de Triatominae). El análisis parasitológico de los $P$. geniculatus capturados fue positivo para flagelados en el intestino posterior, pero no se pudo determinar con certeza la especie de flagelado, debido a que los insectos llevaban varios días de muertos y se encontraban en un alto grado de desecación. En la inspección de palmas y árboles no se hallaron nidos de aves o de otros animales; sin embargo, la comunidad manifestó que el árbol de almendro ubicado en el solar de la casa afectada $\left({ }^{* *}\right)$ usualmente era visitado por diversos animales silvestres para comer sus frutos. En ninguna de las plantas examinadas se detectaron triatominos.

Con referencia a las características de las viviendas, éstas tienen paredes de madera, techo de cinc (unas pocas con techo de paja) y piso de madera; las casas de la zona se construyen separadas del suelo, aproximadamente, $50 \mathrm{~cm}$, para evitar inundaciones cuando sube la marea. Se observó que en los solares almacenan numerosos y diversos objetos (algunos en desuso, otros para la construcción) que pueden favorecer la proliferación de roedores y otros animales (figura 3 ).

Se muestrearon 25 palmeras, discriminadas en 20 ejemplares de palma pangana ( $R$. taedigera) y 5 cocoteros ( $C$. nucifera); igualmente, se muestrearon cuatro almendros ( $T$. catappa) y un ejemplar de mangle bobo (Laguncularia sp.). Debido a que la comunidad basa parte de su economía en el turismo ecológico, no permitieron el derribo de ningún ejemplar vegetal, por lo que en la inspección de las palmeras se eliminaron paulatinamente sólo las hojas más bajas, así como las bases de los pecíolos muertos, que constituirían el abrigo apropiado para los insectos, lo mismo que las inflorescencias de la palma pangana, que son, junto con los frutos, muy empleados en artesanías por los habitantes de la localidad.

En la búsqueda de mamíferos silvestres se logró la captura de un ejemplar adulto hembra de "chucha lanuda" (Caluromys lanatus), el cual fue negativo para infección por $T$. cruzi, mediante pruebas de laboratorio.

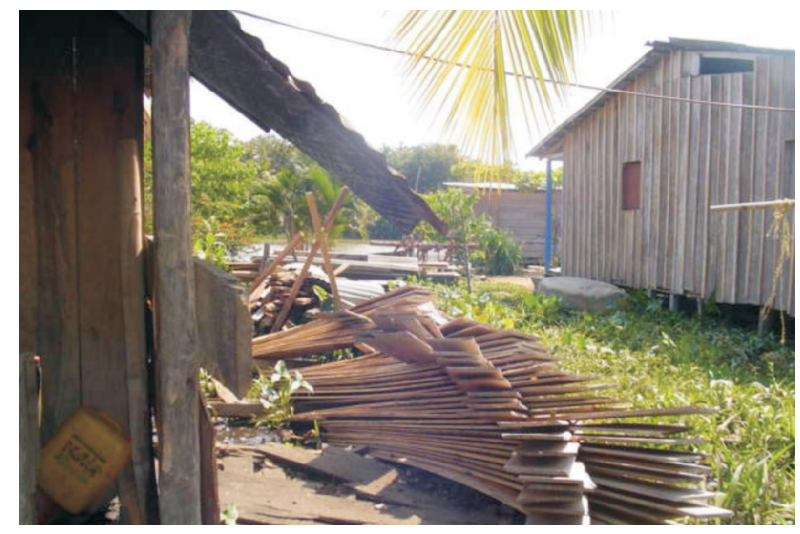

Figura 3. Condiciones de la vivienda. Corregimiento Bocas del Atrato, Turbo, Antioquia

En todos los desplazamientos realizados al corregimiento de Bocas de Atrato, se estableció contacto con la comunidad y se explicaron los mecanismos de transmisión y factores de riesgo para infectarse con este parásito, lo mismo que las medidas de prevención al alcance para prevenir infecciones posteriores. Se enfatizó en la necesidad de consultar oportunamente en aquellos casos en que se presenten síntomas similares a los descritos para la enfermedad.

\section{Discusión}

Mediante el presente estudio se reporta un probable brote agudo de enfermedad de Chagas en el departamento de Antioquia, región que, de acuerdo con la encuesta nacional sobre enfermedad de Chagas realizada entre los años 1998 y 1999, fue clasificada de bajo y mediano riesgo para esta enfermedad, debido a la baja seroprevalencia en menores de edad. Sin embargo, la encuesta nacional antes referenciada, permitió establecer que en la región de Urabá existe una variada fauna de triatomos, y se estableció la presencia de especies con alto significado epidemiológico, como $R$. prolixus y $T$. dimidiata, las cuales no se han hallado colonizando viviendas (Restrepo $\mathrm{M}$, Restrepo BN, Parra GJ. Informe final. Programa Nacional de Prevención y Control de la Enfermedad de Chagas y la Cardiopatía Infantil. Antioquia, Córdoba, Bolívar. Instituto Colombiano de Medicina Tropical, 1999). La especie $R$. prolixus pudo haber llegado a la región debido a transporte pasivo por migraciones, sin que se lograra establecer y colonizar las viviendas. Triatoma dimidiata presenta hábitat silvestre asociado a troncos de árboles $y$, al igual que con $R$. rolixus, no se han encontrado pruebas de domiciliación de esta especie en el Urabá (G. Parra, observación personal). Otras especies de menor importancia epidemiológica, 
como R. pallescens, T. dispar, E. cuspidatus y $P$. geniculatus, son recolectadas esporádicamente en la zona. Eventualmente, han resultado casos de enfermedad de Chagas en pacientes residentes en la zona de Urabá, quienes relatan no haber salido de la región, casos que pueden deberse a intrusiones de triatominos a las casas.

En el presente estudio se encontró que, en el corregimiento de Bocas del Atrato del municipio de Turbo, once personas resultaron afectadas por enfermedad de Chagas, de las cuales una murió y otras diez resultaron positivas para anticuerpos lgG e IgM mediante dos técnicas diferentes: ELISA e IFI. Tres de estos casos fueron positivos en las pruebas de PCR; la detección de anticuerpos IgM en todos los pacientes sintomáticos, está a favor de una infección activa o reciente, hallazgo que respalda la hipótesis de que en la zona se presentó un brote agudo de enfermedad de Chagas. Del mismo modo, la identificación del parásito por técnicas moleculares en algunos de los pacientes (PCR positiva en tres), demuestra circulación del parásito en estas personas e, igualmente, apoya la hipótesis de brote agudo en la zona.

Los resultados negativos del extendido, la gota gruesa y la prueba de Bennett se podrían explicar por la baja parasitemia circulante, la cual no permitió su detección por estas pruebas, pero sí lograron detectarse mediante la PCR.

Otros factores relacionados con las condiciones del transporte de las muestras desde el corregimiento a orillas del río Atrato, procesamiento de las mismas y envío al Instituto Colombiano de Medicina Tropical de Medellín, pudieron haber influido en estos resultados negativos.

En ninguno de los pacientes evaluados se observaron signos de puerta de entrada o chagoma de inoculación, pero sí es importante destacar que en cuatro de los pacientes positivos se presentó edema palpebral bilateral, uno de los signos descritos como sugestivos de la presentación aguda de esta enfermedad y documentado en varios casos con enfermedad de Chagas, registrados en brotes agudos de la enfermedad (24-26).

En el estudio entomológico de las viviendas y del peridomicilio, no se encontró domiciliación por especies de triatominos, hallazgo que con alta probabilidad descarta la transmisión vectorial como causa de este brote. Una hipótesis más acertada sería la transmisión oral mediante la ingestión del parásito $T$. cruzi en alimentos contaminados con restos de triatominos o excrementos de marsupiales infectados, dadas las características de los cuadros clínicos con signos de parasitemia y miocardiopatía chagásica en algunos de los positivos y las circunstancias de relación entre los casos positivos, compartiendo un mismo sitio de alimentación en la casa de uno de los enfermos.

Varios trabajos reportados en la literatura científica, documentan brotes agudos de enfermedad de Chagas por transmisión oral (24-27), destacándose el trabajo reciente de Alarcón de Noya et al., donde describen un brote agudo de enfermedad de Chagas en una área urbana de Carcas, con 103 personas infectadas de 1.000 expuestas, ocasionado probablemente por un jugo de guayaba contaminado con heces de triatominos y consumido por estudiantes de una institución educativa (24). Asimismo, en Brasil se reportó un brote agudo de enfermedad de Chagas por consumo de açai, un fruto de palmera utilizado por la población del Amazonas (27). La Amazonia ha sido el ecosistema donde la transmisión oral de esta enfermedad ha presentado una mayor frecuencia y visibilidad (28). En Colombia se ha documentado también transmisión oral por ingestión de jugos vegetales de palmas, en el sur del departamento del Magdalena (13).

El período de incubación que se refiere para esta vía de transmisión, se ha calculado entre 3 y 22 días (1); en el presente estudio la aparición de casos se extendió por 28 días (figura 4) y, dado el tiempo de evolución de los síntomas referido por los pacientes, podría pensarse que el contagio se produjo en las dos últimas semanas de octubre de 2009, momento en el cual se presentaba una temporada de lluvia que permitía almacenar agua proveniente del techo de la vivienda **, y que no todos los pacientes recibieron el inóculo a la vez, ya que el agua permaneció almacenada durante varios días, según información de los encuestados. No se pudieron tomar muestras para estudio de laboratorio debido a que la poca agua residual que había en el tanque al momento de la investigación llevaba semanas contaminándose con otros materiales. En el presente estudio no se pudo identificar ningún alimento o comida específica durante este período, como posible vehículo de contaminación, y por el tiempo en que se detectaron los casos, tampoco fue posible obtener muestras de los alimentos consumidos para estudios de laboratorio.

Podría especularse que el consumo de agua lluvia obtenida por la recolección guiada desde el techo 


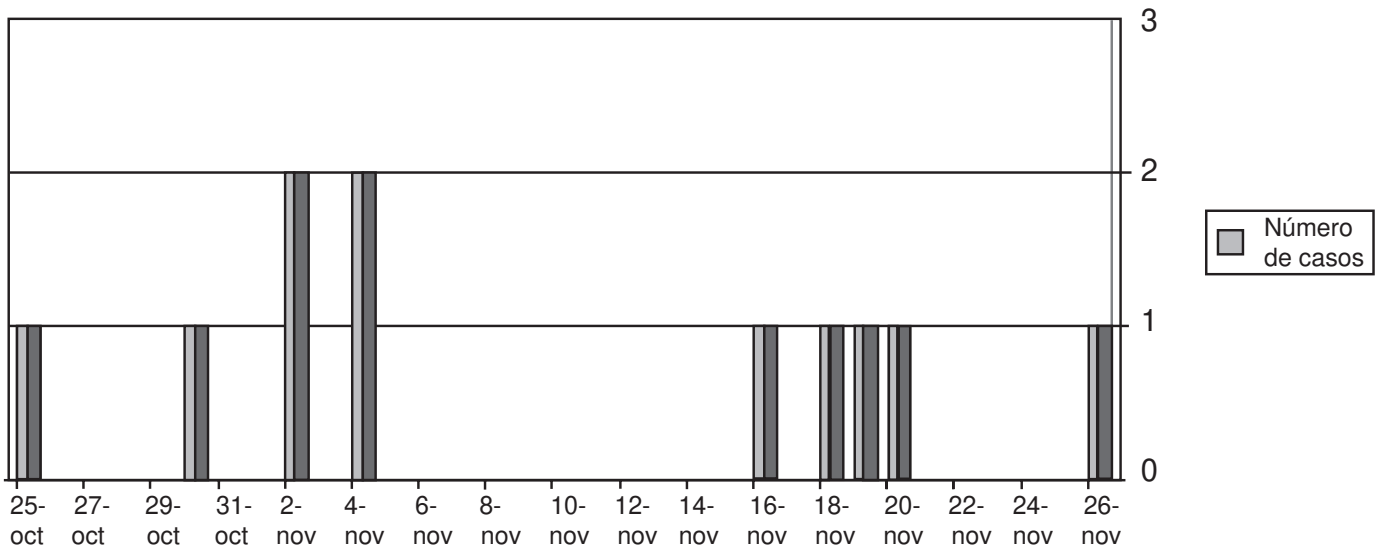

Figura 4. Curva epidémica de 10 pacientes con enfermedad aguda de Chagas, corregimiento Bocas de Atrato, Turbo, 2009

de la vivienda, pudo ser el vehículo que llevó a los alimentos las heces de triatominos o las secreciones de glándulas perianales de animales silvestres (tipo zarigüeyas) que contenían T. cruzi; la costumbre de emplear esta agua sin hervir en la preparación de sus bebidas y alimentos, y la atracción de los animales silvestres a la vivienda por la forma de disposición de los restos alimentarios, hecho referido por los habitantes y corroborado con la captura realizada, pueden complementar esta hipótesis. Sin embargo, como se anotó con anterioridad, en este estudio no se pudo documentar la presencia de $T$. cruzi en agua y se deben realizar estudios que permitan hacerlo.

Otros autores han confirmado la viabilidad del parásito en alimentos y jugo de caña durante 24 horas o más $(29,30)$.

Con respecto a los brotes agudo de enfermedad de Chagas reportados en Colombia, sólo en el brote ocurrido Guamal (Magdalena) (13), se propuso el transporte de heces de triatominos en vino de palma; en los tres otros brotes registrados en Tibú (Norte de Santander) (1), en Bucaramanga (1) y en Lebrija (Santander) (14), no se pudo identificar algún alimento en especial responsable de los brotes, tal como ocurrió en el brote de Bocas de Atrato, objeto del presente estudio.

Llama la atención que el presente brote se registró en noviembre, con probable exposición desde octubre, tal como ocurrió en los pacientes registrados en el brote de Lebrija (Santander) (14) y en el brote urbano de Caracas (Venezuela) (24). No hay razones que expliquen este hallazgo, dado que la presentación de la enfermedad no se ha relacionado con factores climáticos (14).
La captura de un ejemplar de $C$. lanatus confirma la presencia de reservorios silvestres de $T$. cruzien la zona, cerca de la vivienda donde se presentó el brote. Esta especie de marsupial se ha encontrado naturalmente infectada con $T$. cruzi en Venezuela y Brasil (18). Además, es importante resaltar que los marsupiales son considerados importantes reservorios sinantrópicos, debido a que en ellos se lleva a cabo un ciclo especial de $T$. cruzi en sus glándulas anales, similar al que ocurre en los triatominos, con una presencia muy densa de epimastigotes y tripomastigotes metacíclicos (forma infectante), con las que pueden infectar el agua y otros alimentos (19), favoreciendo la transmisión oral de $T$. cruzi.

Debemos resaltar que el presente estudio tiene como limitaciones la demora presentada entre la aparición de los casos y el inicio de la investigación, lo cual conllevó a fallas en la recolección de muestras de alimentos y su análisis, para determinar con precisión las fuentes de infección. La presentación de este probable brote de enfermedad de Chagas en la zona, revela la necesidad de implementar medidas de vigilancia y control que sean rápidas y efectivas, con participación de la comunidad para garantizar la continuidad de las mismas. El municipio de Turbo cuenta con una red de microscopistas y técnicos de saneamiento ambiental que están entrenados para el manejo de la malaria; esta infraestructura podría utilizarse para hacer diagnóstico rápido de $T$. cruzien gota gruesa y para la vigilancia entomológica de los vectores, estrategia usada en otras regiones donde se han presentado situaciones similares (31).

\section{Agradecimientos}

A la comunidad del corregimiento Bocas del Atrato, por su colaboración y disposición en la ejecución 
de las actividades. A las instituciones de salud de los municipios de Turbo y Apartadó, que facilitaron el acceso a la información y el apoyo logístico al equipo de trabajo. Al personal de la Dirección Seccional de Salud y Protección Social de Antioquia, del Instituto Colombiano de Medicina Tropical y del Laboratorio Departamental de Salud Pública de Antioquia, que apoyó el trabajo de campo y de laboratorio. Al Instituto Nacional de Salud, por su apoyo técnico, directrices y medicamentos.

\section{Conflicto de intereses}

Los autores declaran que no existe conflicto de interés.

\section{Financiación}

Este trabajo fue financiado por el programa de Enfermedades Transmitidas por Vectores de la Dirección Seccional de Salud y Protección Social de Antioquia y por el Instituto Colombiano de Medicina Tropical - Universidad CES.

\section{Referencias}

1. Organización Panamericana de la Salud. Guía para vigilancia, prevención, control y manejo clínico de la enfermedad de Chagas aguda transmitida por alimentos. Serie de Manuales Técnicos, 12. Rio de Janeiro: PANAFTOSA-VP/OPAS/OMS; 2009. p. 92.

2. Moncayo A. Chagas disease: Current epidemiological trends after the interruption of vectorial and transfusional transmision in the southern cone countries. Mem Inst Oswaldo Cruz. 2003:98:577-91.

3. Galvão C, Carcavallo RU, Rocha DS, Jurberg J. A checklist of the current valid species of the subfamily Triatominae Jeannel, 1919 (Hemiptera, Reduviidae) and their geographical distribution, with nomenclatural and taxonomic notes. Zootaxa. 2003;202:1-36.

4. Storino R, Jörg $\mathbf{M}$. Vías de infección y aspectos clínicos. En: Storino R, Milei J, editores. Enfermedad de Chagas. Buenos Aires: Ed. Mosby-Doyma de Argentina; 1994. p. 185-207.

5. Nattan-Larrier L. Infections à Trypanosomes et voies de penetrations dês virus. Bull Soc Pathol Exot. 1921;14:53742.

6. Brumpt E. Precis de parasitologíe. Tome 1. Paris: Masson; 1931.

7. Kofoid CA, Donat F. Experimental infection with Trypanosoma cruzi from the intestine of cone-nose bug Triatoma protracta. Proc Soc Exp Biol Med. 1933;30:48991.

8. Cardoso FA. Sur le mechanisme de la transmission de la maladie de Chagas. Annales de Parasitologíe Humaine. 1933:16:341-9.

9. Mazza S, Montana A, Benítez C, Juzin E. Transmisión del Schizotrypanum cruzi al niño por leche de madre con enfermedad de Chagas. MEPRA. 1936;28:41-6.
10. Mayer HF. Infección experimental con Trypanosoma cruzi por vía digestiva. An Inst Med Region (Corrientes). 1961;5:43-8.

11. Díaz-Ungría C. Transmission of Trypanosoma cruzi in mammals. Ann Parasitol Hum Comp. 1966;41:549-71.

12. Díaz-Ungría C, Zeuss M. Transmisión del Trypanosoma evansi y del Trypanosoma cruzi a partir de heces de animales infectados por vía bucal. Revista Veterinaria Venezolana. 1971;30:187.

13. Cáceres D, Nicholls RS, Corredor A, Gualdrón L, Slait E, Dib J, et al. Investigación de un brote de síndrome febril con miocarditis aguda en Guamal, Magdalena, 7 a 11 de junio de 1999. Inf Quinc Epidemiol Nac. 1999;4:170-8.

14. Hernández LM, Ramírez A, Cucunubá Z, Zambrano P. Brote de Chagas agudo en Lebrija, Santander, 2008. Revista del Observatorio Salud Pública de Santander. 2009;4:28-36.

15. Ministerio de la Protección Social de Colombia. Primer brote de Chagas agudo en Aguachica, Cesar. Consultado: 30 de octubre de 2010. Disponible en: http://www. minproteccionsocial.gov.co/comunicadosPrensa/Paginas/C onfirmadoprimerbrotedechagasagudaenAguachica,Cesar. aspx

16. Voller A, Bartlett A, Bidwell DE. Enzyme immunoassays for parasitic disease. Trans R Soc Trop Med Hyg. 1976;70:98105

17. Guhl F, Nicholls S. Manual de procedimientos para el diagnóstico de la enfermedad de Chagas. Bogotá D.C.: Quebecor impresores; 2001. p. 98.

18. Camargo ME. Fluorescent antibody test for the serodiagnosis of American tripanosomiasis. Technical modification employing preserved culture forms of Trypanosoma cruzi in a slide test. Rev Inst Med Trop Sao Paulo. 1966;8:227-34.

19. Sturm NR, Degrave W, Morel C, Simpson L. Sensitive detection and schizodeme classification of $T$. cruzi cells by amplification of kinetoplastid minicircle DNA sequences: Use in diagnosis of chagas disease. Mol Biochem Parasitol. 1989;33:205-14

20. Schijman AG, Altcheh J, Burgos JM, Biancardi M, Bisio M, Levin MJ, et al. Aetiological treatment of congenital Chagas' disease diagnosed and monitored by the polymerase chain reaction. J Antimicrob Chemother. 2003;52:441-9.

21. Prata A. Tripanosomiasis americana. En: Goldsmith R, Heyneman D, editores. Parasitología y medicina tropical. $1^{\underline{a}}$ edición. México, D.F.: El Manual Moderno; 1995. p. 34648.

22. Feliciangeli D, Hernández M, Suárez B, Martínez C, Bravo A, Bracho J, et al. Comparación de métodos de captura intradoméstica de triatominos vectores de la enfermedad de Chagas en Venezuela. Bol Mal Salud Amb. 2007;47:103-17.

23. Lent $\mathbf{H}$, Wygodzinsky P. Revision of the Triatominae (Hemiptera, Reduviidae), and their significance as vectors of Chagas disease. Bull Am Mus Nat Hist. 1979;163:123-520.

24. Alarcón de Noya B, Díaz-Bello Z, Colmenares C, RuizGuevara R, Mauriello L, Zavala-Jaspe R. et al. Large urban outbreak of orally acquired acute Chagas disease at a school in Caracas, Venezuela. J Infect Dis. 2010;201:1308-15. 
25. Dias JP, Bastos C, Araújo E, Mascarenhas AV, Netto EM, Grassi $F$, et al. Acute Chagas disease outbreak associated with oral transmission. Rev Soc Bras Med Trop. 2008;41:296-300.

26. Bastos CJ, Aras R, Mota G, Reis F, Dias JP, de Jesus RS, et al. Clinical outcomes of thirteen patients with acute Chagas disease acquired through oral transmission from two urban outbreaks in Northeastern Brazil. PLoS Negl Trop Dis. 2010;4:e711.

27. Nóbrega AA, García MH, Tatto E, Obara MT, Costa E, Sobel $\mathrm{J}$, et al. Oral transmission of Chagas disease by consumption of açaí palm fruit, Brazil. Emerg Infect Dis. 2009;15:653-5.

28. Organización Panamericana de la Salud, Unidad Regional de Prevención y Control de Enfermedades Transmisibles (DPC/CD/CHA), Grupo Técnico Especializado en Inocuidad de Alimentos (DPC/VP/
FOS). Informe de la consulta técnica en epidemiología, prevención y manejo de la transmisión de la enfermedad de Chagas como enfermedad transmitida por alimentos (ETA). Rio de Janeiro: OPS; 2006. p. 46.

29. Pinto Dias J. Notas sobre o Trypanosoma cruzi e suas características bio-ecológicas, como agente de enfermidades transmitidas por alimentos. Rev Soc Bras Med Trop. 2006;39:370-5.

30. Pinto PL, Amato Neto V, Nascimento SA, Souza HB, Myamoto A, Moreira AA, et al. Observações sobre a viabilidade do Trypanosoma cruzi no caldo de cana. Rev Inst Med Trop Sao Paulo. 1990;32:325-7.

31. World Health Organ. Control of Chagas disease. Second report of the WHO Expert Committee. World Health Organ Tech Rep Ser. Geneve: WHO; 2002. p. 905. Consultado: 25 de marzo 2010. Disponible en: http://whqlibdoc.who.int/trs/ WHO_TRS_905.pdf. 